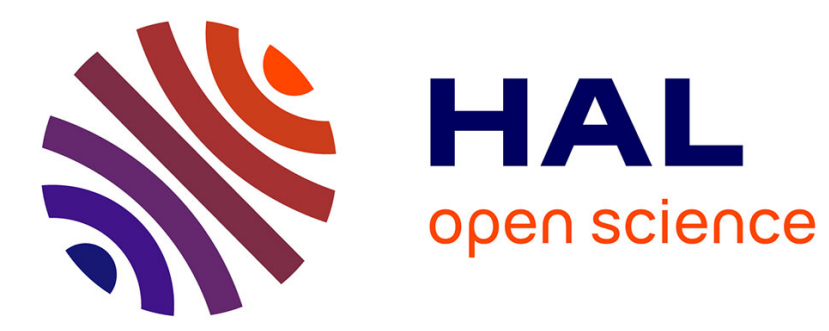

\title{
Thermal oxidation of poly(Dicyclopentadiene) - Decomposition of hydroperoxides
}

Jing Huang, Wendy Minne, Renata Drozdzak, Gilles Recher, Pierre Yves Le Gac, Emmanuel Richaud

\section{- To cite this version:}

Jing Huang, Wendy Minne, Renata Drozdzak, Gilles Recher, Pierre Yves Le Gac, et al.. Thermal oxidation of poly(Dicyclopentadiene) - Decomposition of hydroperoxides. Polymer Degradation and Stability, 2020, 174, pp.1-14. 10.1016/j.polymdegradstab.2020.109102 . hal-02531324

\section{HAL Id: hal-02531324 \\ https://hal.science/hal-02531324}

Submitted on 3 Apr 2020

HAL is a multi-disciplinary open access archive for the deposit and dissemination of scientific research documents, whether they are published or not. The documents may come from teaching and research institutions in France or abroad, or from public or private research centers.
L'archive ouverte pluridisciplinaire HAL, est destinée au dépôt et à la diffusion de documents scientifiques de niveau recherche, publiés ou non, émanant des établissements d'enseignement et de recherche français ou étrangers, des laboratoires publics ou privés. 


\title{
Thermal oxidation of poly(Dicyclopentadiene) - Decomposition of hydroperoxides
}

\author{
Jing Huang a , Wendy Minne ${ }^{\mathrm{b}}$, Renata Drozdzak ${ }^{\mathrm{b}}$, Gilles Recher ${ }^{\mathrm{b}}$, Pierre Yves Le Gac ${ }^{\mathrm{c}}$, \\ Emmanuel Richaud ${ }^{\text {a, * }}$ \\ a Arts et Metiers Institute of Technology, CNRS, CNAM, PIMM, HESAM Université, F-75013, Paris, France \\ b TELENE SAS, 2 rue Marie Curie, 2 Rue Marie Curie, 59910, Bondues, France \\ c IFREMER, Service Matériaux et Structures, Centre de Brest BP70, 29280, Plouzané, France
}

Keywords:

Polydicyclopentadiene

Thermal oxidation

Hydroperoxide decomposition

Polymerization catalysts

\begin{abstract}
A B S T R A C T
Thin unstabilized PDCPD film were thermally oxidized in ovens at several temperatures ranging from $50{ }^{\circ} \mathrm{C}$ to $120{ }^{\circ} \mathrm{C}$. Hydroperoxide concentration was monitored by DSC. It was observed that hydroperoxides concentration reaches a plateau with short induction times, for example around $8 \mathrm{~h}$ at $50^{\circ} \mathrm{C}$. This plateau occurs at very high concentration, around about $1 \mathrm{~mol} \mathrm{l}^{-1}$ at $50{ }^{\circ} \mathrm{C}$. In order to study both the chemical mechanisms and the kinetics of hydroperoxides decomposition, oxidized samples were thermally aged in an inert atmosphere to destroy hydroperoxides. For initially high concentrations corresponding to the plateau, it was shown that hydroperoxides decompose following a bimolecular process, the rate constant of which being calculated from the hydroperoxide depletion curves. The comparison of samples containing different polymerization catalyst amounts suggested the co-existence of an unimolecular process. This process mainly occurs at low hydroperoxides concentrations and slightly influences the overall oxidation process.
\end{abstract}

\section{Introduction}

The polydicyclopentadiene (PDCPD) thermal oxidation was shown to induce an increase in $\mathrm{T}_{\mathrm{g}}$ and yield stress, which was linked to a predominant crosslinking mechanism. The relative fastness of PDCPD oxidation compared to other unsaturated substrates (elastomers oxidized in their rubbery state) was first ascribed to the PDCPD glassy state involving a low termination rate between peroxy radicals [1], as evidenced from selective experiments under elevated oxygen pressures allowing the assessment of $\mathrm{POO}^{\circ}+\mathrm{POO}^{\circ}$ termination rate constant [2].

Another possible reason to explain the high oxidation of thin PDCPD samples was the high initiation rate (i.e. rate of radical creation) [1,3]. In polymers below $150{ }^{\circ} \mathrm{C}$, there are several reasons to assume that the radical creation comes from defects found in (very) small concentration and from hydroperoxide decomposition. The latter becoming the main source of radicals creation at fast rates [4].

\footnotetext{
* Corresponding author.

E-mail address: emmanuel.richaud@ensam.eu (E. Richaud).
}

The rate constant for bimolecular $\mathrm{POOH}$ decomposition can in principle be determined from the modeling (fitting) of induction period length under oxygen excess whereas the unimolecular one could be estimated from the oxidation kinetics under lower oxygen pressure [5]. However, such method remains questionable since some other parameters (for example initial $\mathrm{POOH}$ concentration and propagation rate constants) must be somewhat arbitrarily fixed. In our last paper [2], we made the ad hoc assumption that oxidation was bimolecular (in term of radical creation by hydroperoxide decomposition) at least in the steady state but an unimolecular initiation reaction was also needed to fit the curves. The corresponding rate constants were only determined from curves "best fitting" and their values remain to us questionable. Last, we observed very high values of those initiation rate constants which were assumed to be linked with the presence of catalyst used for metathesis polymerization but the effect of these on the hydroperoxide decomposition remained to be better illustrated and quantified for us.

To investigate those questions linked to hydroperoxide decomposition, which is the aim of the present paper, we implemented here an alternative approach inspired from the analysis of signal related to peroxides or half time analysis [6-8] but using DSC 
Table 1

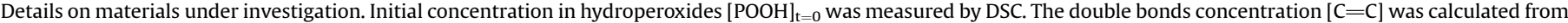
733,973 and $3049 \mathrm{~cm}^{-1}$ absorption [2]. NB: antioxidants, if any, were removed by $\mathrm{CH}_{2} \mathrm{Cl}_{2}$ extraction overnight.

\begin{tabular}{|c|c|c|c|c|c|}
\hline Material & Catalyst structure & Catalyst concentration $\left(\mathrm{mol} \mathrm{kg}^{-1}\right)$ & Antioxidant (in \% mass fraction) & {$[\mathrm{C}=\mathrm{C}]\left(\mathrm{mol} \mathrm{l}^{-1}\right)$} & {$[\mathrm{POOH}]_{\mathrm{t}=0}\left(\mathrm{~mol} \mathrm{l}^{-1}\right)$} \\
\hline $\mathrm{M}^{*}$-PDCPD & Ru1 $=$ & $2.5210^{-4}$ & $1 \%$ & 13 & 0.001 \\
\hline L-PDCPD & Ru2 & $1.1810^{-4}$ & 1 & 11 & 0.024 \\
\hline H-PDCPD & Ru2 & $3.5310^{-4}$ & i & 11 & 0.013 \\
\hline
\end{tabular}

instead of chemiluminescence, the advantage of DSC being more directly related to residual peroxides concentration [1]:

- selective thermolysis experiments with varying initial $\mathrm{POOH}$ concentration (being obtained from thermal oxidation experiments carried out at varying temperature and exposure times),

- comparisons of PDCPD with various residual amounts of organometallic Ring Opening Metathesis Polymerization catalysts (here Ruthenium based), since it is actually known that metallic ions (originating either from catalyst or sometimes fillers such clay) can be detrimental to the long term stability [9-11].

\section{Experimental}

\subsection{Material}

The samples under investigation were supplied as stabilized bulk material prepared by reaction injection molding process (RIM) at about $40{ }^{\circ} \mathrm{C}$. The catalyst used and the other information are summarized in Table 1. Films of 6-15 $\mu \mathrm{m}$ thickness were obtained by cutting the bulk material with a microtome (RM 2255 Leica), and then theses ones were purified by refluxing in $\mathrm{CH}_{2} \mathrm{Cl}_{2}$ (270997 Sigma-Aldrich) overnight. Unstabilized samples were stored in freezer $\left(-20^{\circ} \mathrm{C}\right)$ for maximum 7 days before ageing.

Three materials were considered here. They were all synthesized using Ruthenium catalyst (Ru1 or Ru2), with low (L-PDCPD), medium ( $\mathrm{M}^{*}$-PDCPD) and high (H-PDCPD) catalyst concentration. The structure of the Ru1 catalyst used for $\mathrm{M}^{*}$-PDCPD is given in Table 1. Ru2 catalyst used for synthesizing both L- and H-PDCPD differs from Ru1 by some substituent groups and is not given here because of confidentiality reasons.

According to the mechanism of Ring Opening Metathesis Polymerization, Ru based molecules are covalently bonded with polymer chains and would not be extractible during the purification process. It must be noted that ruthenium weight ratio is under the detection limits of elementary analysis and this last assumption could not be checked.

\subsection{Ageing and characterization}

\subsubsection{Ageing}

Samples were aged at $50,70,90$ and $120^{\circ} \mathrm{C}$ in ventilated ovens (supplied by System Climatic Service).

\subsubsection{In situ hydroperoxides decomposition and quantification by differential scanning calorimetry (DSC)}

Aged films were first analyzed using DSC in order to quantify peroxides by submitting aged samples to a heating ramp under nitrogen at a $10{ }^{\circ} \mathrm{C} \mathrm{min}-1$ rate. The exotherm ascribed to $\mathrm{POOH}$ decomposition was converted into concentration using $\Delta \mathrm{H}_{\mathrm{POOH}}=440 \mathrm{~kJ} \mathrm{~mol}^{-1}[1]$ by the formula:

$[\mathrm{POOH}]=\Delta \mathrm{H} / \Delta \mathrm{H}_{\mathrm{POOH}}$

Where $\Delta \mathrm{H}$ is the measured enthalpy (in $\mathrm{kJ} \mathrm{kg}^{-1}$ ) and $\Delta \mathrm{H}_{0}$ the molar enthalpy for the hydroperoxide decomposition $\left(\mathrm{kJ} \mathrm{mol}^{-1}\right)$ determined either from theoretical [12] assessment or correlation between DSC analysis and direct chemical treatments (by iodometry for example [1,13]).

To better understand the stability of peroxides, the following procedure was used for samples thermally oxidized under air (with a concentration equal to $[\mathrm{POOH}]_{0}$ after ageing):

- heating to the ageing temperature under nitrogen at a $10{ }^{\circ} \mathrm{C}$ $\mathrm{min}^{-1}$ rate

- isothermal under nitrogen at temperatures ranging from $50{ }^{\circ} \mathrm{C}$ to $120^{\circ} \mathrm{C}$ (where hydroperoxides undergo decomposition)

- jump to $25{ }^{\circ} \mathrm{C}$ and subsequent heating to $300{ }^{\circ} \mathrm{C}$ under nitrogen by $10{ }^{\circ} \mathrm{C} \mathrm{min}{ }^{-1}$ heating rate, this last step allows the titration of residual peroxides after thermolysis (expressed by [POOH]).

Analyses were done using a DSC Q10 apparatus (TA Instruments) with Aluminum pans and lids under $50 \mathrm{ml} \mathrm{min}^{-1} \mathrm{ni}-$ trogen flow. Results were analyzed using TA Analysis software.

\subsubsection{Sulphur dioxide and dimethyl sulfide chemical treatments}

Sulphur dioxide $\left(\mathrm{SO}_{2}\right)$ treatments were used to verify the appearance of hydroperoxides, which transforms $\mathrm{POOH}$ into sulfates by the following reactions [14]:

$\mathrm{POOH}+\mathrm{SO}_{2} \rightarrow \mathrm{PO}-\mathrm{SO}_{2}-\mathrm{OH}$

$$
\mathrm{PO}-\mathrm{SO}_{2}-\mathrm{OH}+\mathrm{POOH} \rightarrow \mathrm{POOP}+\mathrm{H}_{2} \mathrm{SO}_{4}
$$

Dimethyl sulfide (DMS) treatments were also conducted to confirm the appearance of hydroperoxides [14]:

$$
\begin{aligned}
& \mathrm{CH}_{3}-\mathrm{S}-\mathrm{CH}_{3}+\mathrm{P}(=\mathrm{O})-\mathrm{OOH} \rightarrow \mathrm{CH}_{3}-\mathrm{S}(=\mathrm{O})-\mathrm{CH}_{3}+\mathrm{P}(=\mathrm{O})-\mathrm{OH} \text { (fast) } \\
& \mathrm{CH}_{3}-\mathrm{S}-\mathrm{CH}_{3}+\mathrm{POOH} \rightarrow \mathrm{CH}_{3}-\mathrm{S}(=\mathrm{O})-\mathrm{CH}_{3}+\mathrm{POH} \text { (slow) }
\end{aligned}
$$


Table 2

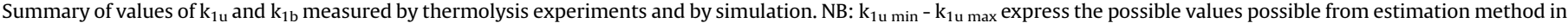
Fig. 12.

\begin{tabular}{|c|c|c|c|c|}
\hline Material & L, M, H-PDCPD & L-PDCPD & $\mathrm{M}^{*}$-PDCPD & H-PDCPD \\
\hline $\begin{array}{l}\text { Catalyst concentration (mol } \\
\mathrm{kg}^{-1} \text { ) }\end{array}$ & & $1.18 .10^{-4}$ & $2.52 .10^{-4}$ & $3.53 .10^{-4}$ \\
\hline Rate constants & $\mathrm{k}_{1 \mathrm{~b}}\left(1 \mathrm{~mol}^{-1} \mathrm{~s}^{-1}\right)$ & $\mathrm{k}_{1 \mathrm{u}}\left(\mathrm{s}^{-1}\right)$ & & \\
\hline Estimation method & Treatment of experimental data (Fig. 9) & $\begin{array}{l}\text { Simulation of thermolysis } \\
\text { (Fig. 12) }\end{array}$ & $\begin{array}{l}\text { Simulation of } \\
\text { thermolysis }\end{array}$ & $\begin{array}{l}\text { Simulation of thermolysis } \\
\text { (Fig. 12) }\end{array}$ \\
\hline $\mathrm{T}=50{ }^{\circ} \mathrm{C}$ & $2.02 \times 10^{-6}$ & $0.8 \times 10^{-6}-1.0 \times 10^{-6}$ & 1 & $3.5 \times 10^{-6}-4 \times 10^{-6}$ \\
\hline $\mathrm{T}=90^{\circ} \mathrm{C}$ & $2.33 \times 10^{-5}$ & $2.5 \times 10^{-5}-4.5 \times 10^{-5}$ & 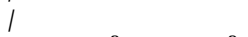 & $1 \times 10^{-4}-1.2 \times 10^{-4}$ \\
\hline $\mathrm{T}=120^{\circ} \mathrm{C}$ & $1.29 \times 10^{-4}$ & $1.6 \times 10^{-3}-1.9 \times 10^{-3}$ & $2.8 \times 10^{-3}-3 \times 10^{-3}$ & $3.3 \times 10^{-3}-3.6 \times 10^{-3}$ \\
\hline $\mathrm{E}_{\mathrm{a}}\left(\mathrm{kJ} \mathrm{mol}^{-1}\right)$ & 62 & 1 & 1 & 1 \\
\hline $\mathrm{R}^{2}$ & 0.9999 & i & l & i \\
\hline
\end{tabular}

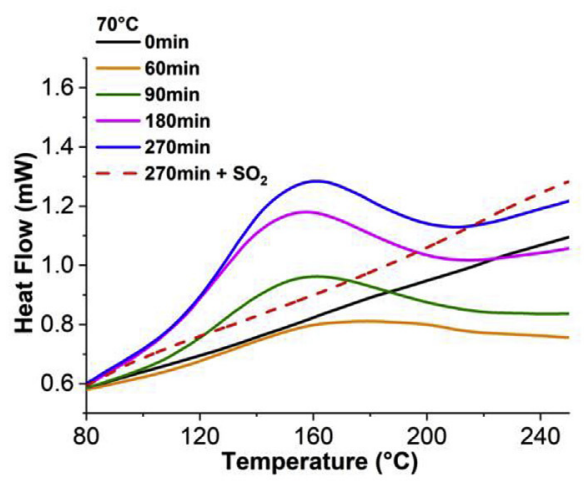

(a)

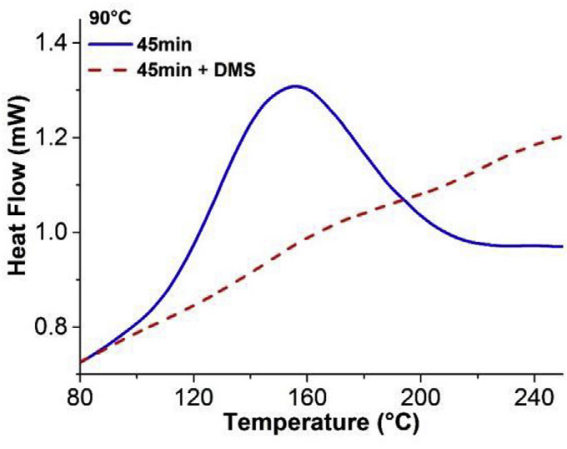

(b)

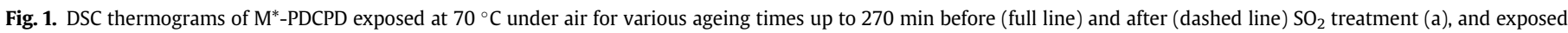
$45 \mathrm{~min}$ at $90{ }^{\circ} \mathrm{C}$ under air before (full line) and after (dashed line) DMS treatment (b).

Degraded samples $(5 \mathrm{mg}$ ) were placed in closed vessels and immersed:

- either in solutions of $5 \mathrm{mg}$ of $\mathrm{Na}_{2} \mathrm{SO}_{3}$ (ref 71988 Sigma Aldrich) in $10 \mathrm{ml} \mathrm{HCl}$ (ref 40253 Sigma Aldrich, $37 \mathrm{wt} \%$ in $\mathrm{H}_{2} \mathrm{O}$ ) in which $\mathrm{SO}_{2}$ was generated in situ,

- or in $10 \mathrm{ml}$ DMS for $24 \mathrm{~h}$ at room temperature.

\subsubsection{Molecular changes observed by FTIR}

Samples were characterized by Fourier Transform InfraRed spectroscopy using a Frontier apparatus (PerkinElmer). Analyses were conducted in the 400 to $4000 \mathrm{~cm}^{-1}$ spectral range by averaging 4 scans at a $4 \mathrm{~cm}^{-1}$ resolution. Spectra were exploited using Spectrum software. In particular, we focused on the carbonyl absorbance (1850-1650 $\mathrm{cm}^{-1}$ ) which was converted into concentration using Beer Lambert law with $3001 \mathrm{~mol}^{-1} \mathrm{~cm}^{-1}$ as molar absorptivity [1,2].

\section{Results}

\subsection{Hydroperoxides production in thermal oxidation}

Titration of hydroperoxides in PDCPD by DSC was already presented in our previous papers [1,3]. An exothermic peak starting at about $80^{\circ} \mathrm{C}$ with a maximal heat release centered at $150{ }^{\circ} \mathrm{C}$ (Fig. 1 , where thermograms are given for samples after various ageing times under air). This signal is totally removed by $\mathrm{SO}_{2}$ (Fig. 1a) or DMS treatment (Fig. 1b). It shows that the species responsible for the exotherm monitored by DSC are hydroperoxides (associated or not $[15,16])$.

Using data from Fig. 1, it is possible to measure the hydroperoxide concentrations during thermal oxidation of PDCPD. Results are plotted in Fig. 2 for several ageing temperatures. For example, the $\mathrm{POOH}$ concentration at $50{ }^{\circ} \mathrm{C}$ increases rapidly in the initial period to reach a value of about $1.5 \mathrm{~mol} \mathrm{l}^{-1}$ after $10 \mathrm{~h}$ of exposure. A pseudo plateau was observed for each exposure conditions under investigation (50-120 ${ }^{\circ} \mathrm{C}$ under atmospheric air).

\subsection{Thermolysis of hydroperoxides}

In order to investigate decomposition of hydroperoxides in PDCPD, thin samples were first oxidized under air (to reach a concentration denoted by $[\mathrm{POOH}]_{0}$ as given in Figs. 4, 8, 9 and 11). They were later in situ thermally aged using DSC under nitrogen atmosphere, after which residual hydroperoxides concentration was measured. Typical results are plotted in Fig. 3.

Two kinds of samples have been considered in this study:

- samples with a high concentration of hydroperoxides (i.e. when the plateau is reached)

- samples with a much lower hydroperoxide concentration (typically $[\mathrm{POOH}]_{0}-0.1-0.3 \mathrm{~mol} \mathrm{l}^{-1}$ ) so as to consider early state of the degradation. 


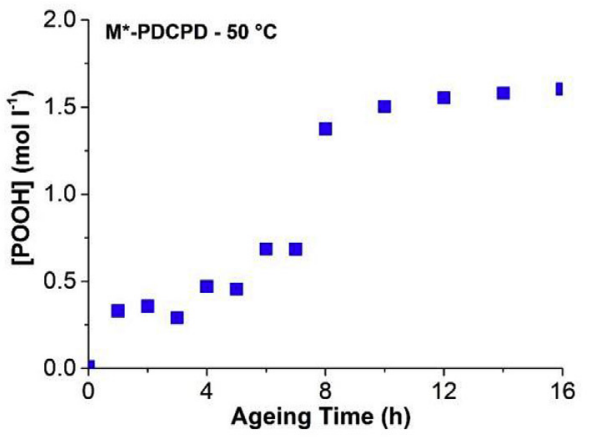

(a)

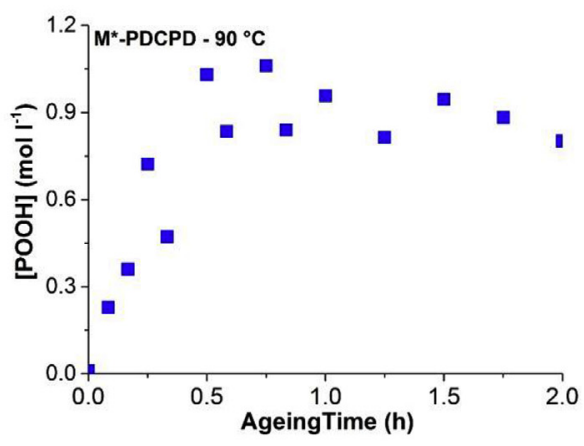

(c)

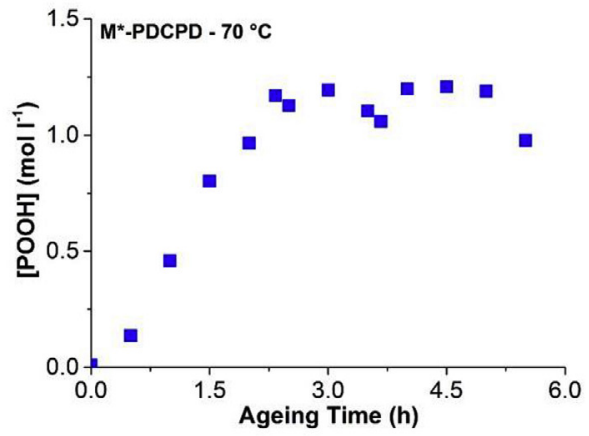

(b)

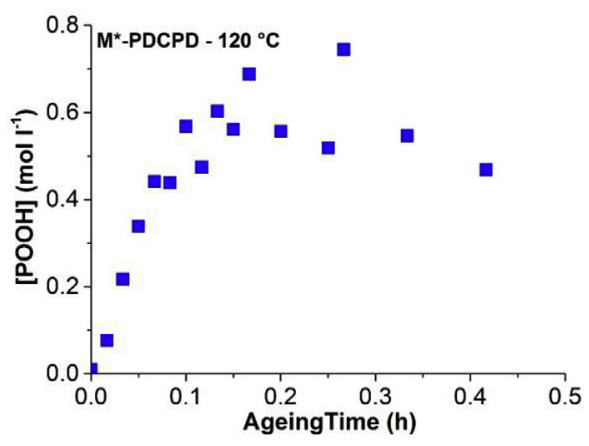

(d)

Fig. 2. Changes in hydroperoxides concentration for thermal oxidation in PDCPD medium* at 50 (a), 70 (b), 90 (c) and $120{ }^{\circ} \mathrm{C}$ (d).

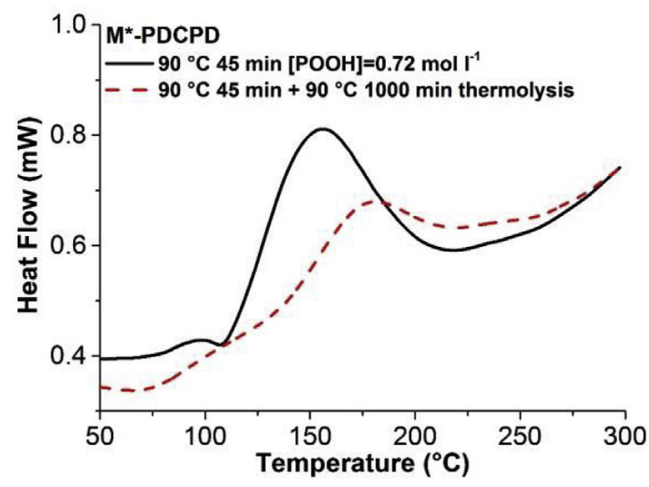

Fig. 3. DSC thermograms before (full line) and after 1000 min thermolysis at $90{ }^{\circ} \mathrm{C}$ (dashed line) for $\mathrm{M}^{*}$-PDCPD exposed $45 \mathrm{~min}$ at $90{ }^{\circ} \mathrm{C}$ under air.

Results for $\mathrm{M}^{*}$-PDCPD are presented in Fig. 4.

The changes in residual concentration (normalized by the initial concentration after ageing under air i.e. at the beginning of thermolysis and expressed by $[\mathrm{POOH}]_{0}$ ) versus thermolysis time are given in Fig. 4. They display an auto-decelerated shape. The time to reach for example $[\mathrm{POOH}] /[\mathrm{POOH}]_{0}=0.5$ clearly decreases with temperature (about $2 \mathrm{~h}$ at $120^{\circ} \mathrm{C}, 7 \mathrm{~h}$ at $90^{\circ} \mathrm{C}$, more than $100 \mathrm{~h}$ at $50^{\circ} \mathrm{C}$ ).

Those sets of experiments were completed by investigating the kinetics of thermolysis in the "low concentration domain" (i.e. for samples oxidized during low exposure times: $1 \mathrm{~min}$ at $120^{\circ} \mathrm{C}$ under air, $\left.[\mathrm{POOH}]_{0}=0.33 \mathrm{~mol} \mathrm{l}^{-1}\right)$. In this case, the time needed for $[\mathrm{POOH}] /[\mathrm{POOH}]_{0}=0.5$ is only 4 min showing that the thermolysis mechanism is different in the "low concentration" and "high concentration" domains as it will be developed later.
The molecular changes observed by FTIR during those thermolysis experiments are shown in Fig. 5. These results call for the following comments:

- Thermolysis always generates a decrease of hydroxyl band at $3400 \mathrm{~cm}^{-1}$, and an increase of carbonyl band centered at $1710 \mathrm{~cm}^{-1}$ independent of temperature (Fig. 5a). This suggests that there is no difference between carbonyl functions generated from alkoxyl radical (i.e. peroxide decomposition during either thermolysis or more generally thermal oxidation) in the investigated temperature range.

Using the difference in hydroperoxides concentration values $\Delta$ $[\mathrm{POOH}]$ (from DSC measurement) and the corresponding increase in carbonyl concentration $\Delta[\mathrm{P}=\mathrm{O}]$ (from FTIR), the apparent carbonyl yield from $\mathrm{POOH}$ decomposition $\left(\gamma_{1}\right)$ can be obtained (Eq. (2)):

$\gamma_{1}=\Delta[\mathrm{P}=\mathrm{O}] / \Delta[\mathrm{POOH}]$

Eq. 2

$\gamma_{1}$ stays almost constant (ca 0.5 ) with temperature (Fig. 5b). This value is higher than the value used for numerical simulation [2] or experimental data on polyisoprene [17]. $\gamma_{1}$ may be here overestimated because the thermolysis process also generates some peroxy radicals that can create other carbonyls for example from termination reactions (see Appendix 1).

\subsection{Effect of catalyst}

The oxidation kinetics of H-PDCPD and L-PDCPD catalysts PDCPD grades were compared (NB: PDCPD medium* was not studied here because it was not polymerized in the same conditions 


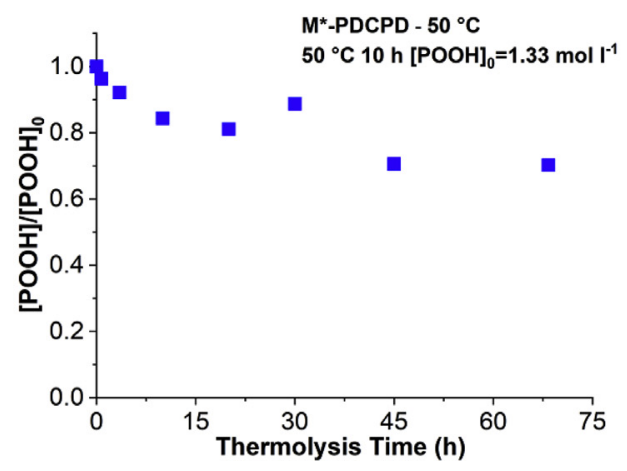

(a)

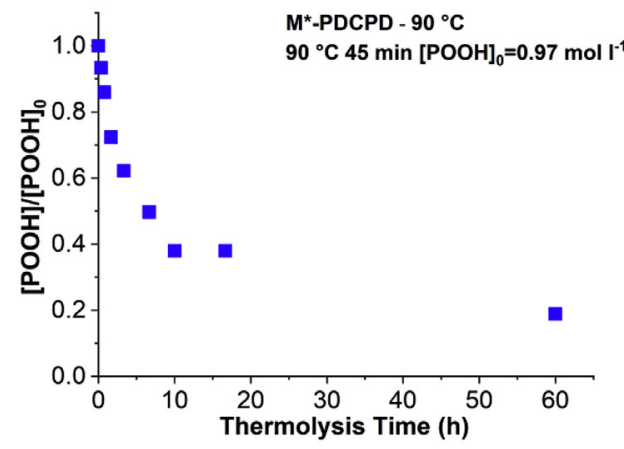

(b)

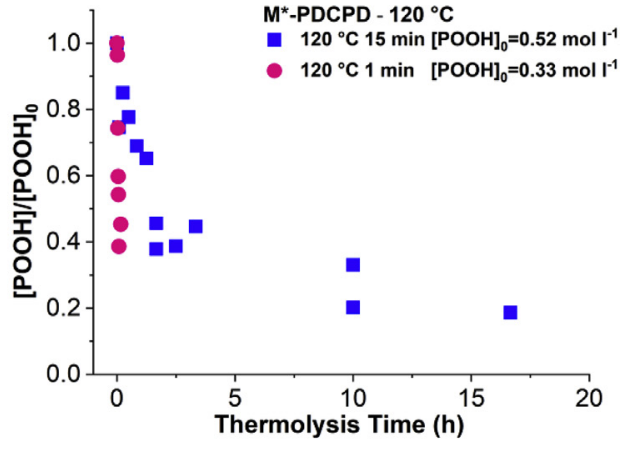

(c)

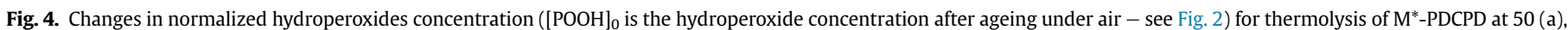
90 (b) and $120^{\circ} \mathrm{C}$ (c). NB: time to totally destroy $\mathrm{POOH}$ at $50{ }^{\circ} \mathrm{C}$ was too long so that thermolysis were interrupted after $70 \mathrm{~h}$

and does not display the same concentration in double bonds as the H-PDCPD and the L-PDCPD). It must be specified that $[\mathrm{POOH}]_{t=0}$ (before any ageing) was measured by DSC close to $0.024 \mathrm{~mol} \mathrm{l}^{-1}$ for L-PDCPD and $0.013 \mathrm{~mol} \mathrm{l}^{-1}$ for H-PDCPD.

Results are presented in Fig. 6 for hydroperoxides and carbonyls concentrations. It shows that the presence of catalysts does not significantly change the overall kinetic curves for $\mathrm{POOH}$ whatever the temperature. As it will be seen later from Eqs. (11) and (12), the small differences would rather come from experimental uncertainties than physical reasons associated to differences in catalyst concentration. In the meantime, results clearly show that the kinetics of carbonyl build-up are rather close for the two catalyst levels considered here. This is in particularly true for the induction period value and confirms the previous conclusion. A small but non negligible difference exists after the end of the induction period when the rate for carbonyl buildup is maximal. The latter will be discussed by kinetic modeling (Appendix 3). In other words, it seems that the presence of catalyst accelerates the polymerization process with only a minor detrimental effect on polymer stability.

The molecular changes of L-PDCPD and H-PDCPD with ageing time (Fig. 7) display the classic features of thermal oxidation. An increase of hydroxyl band at ca $3400 \mathrm{~cm}^{-1}$ corresponds to oxidation products (e.g. hydroperoxides, alcohols or carboxylic acids) occurring in the thermal oxidation of other hydrocarbon polymers.

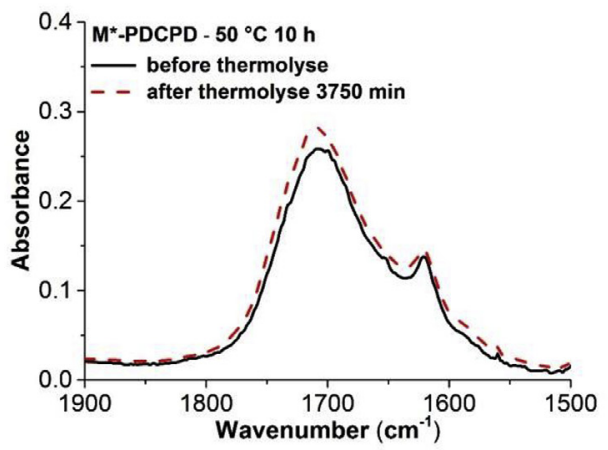

(a)

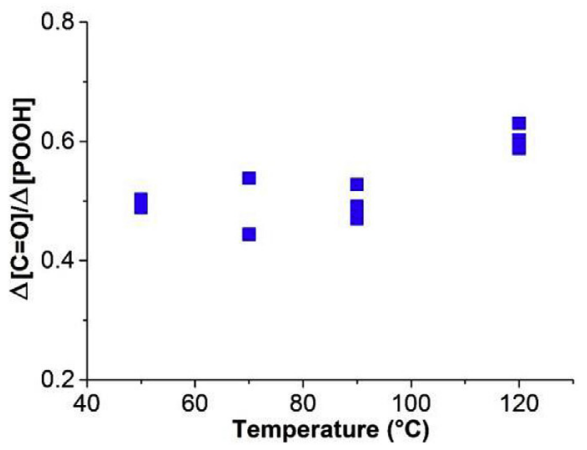

(b)

Fig. 5. FTIR spectra for PDCPD before (full line) and after (dashed line) thermolysis at $50{ }^{\circ} \mathrm{C}(\mathrm{a})$ and apparent carbonyl yield as a function of temperature (b). 


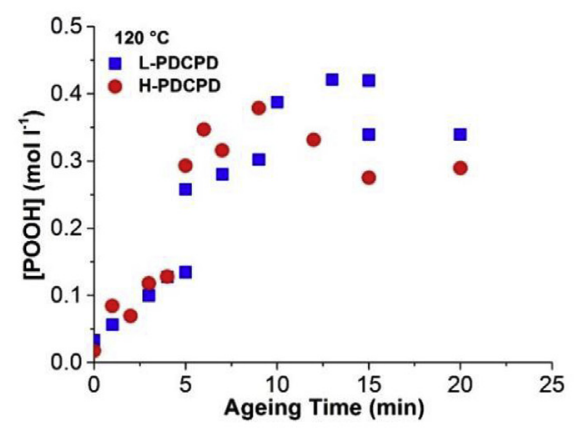

(a)

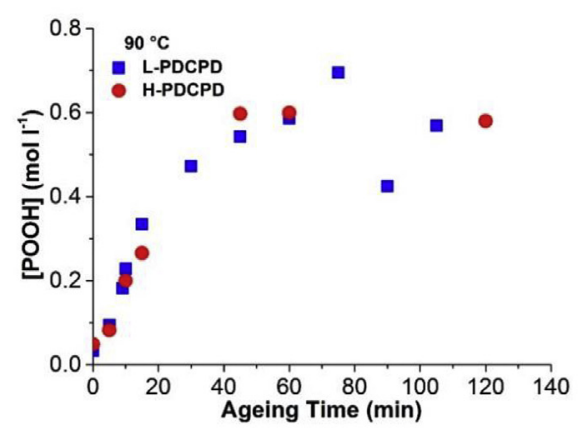

(c)

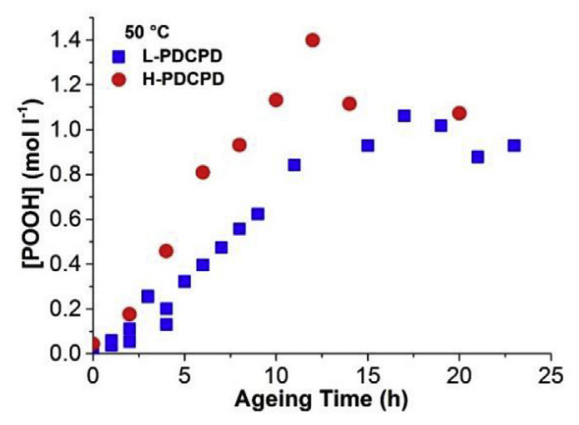

(e)

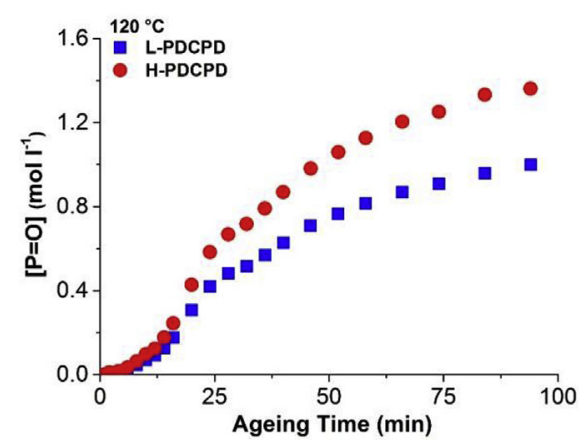

(b)

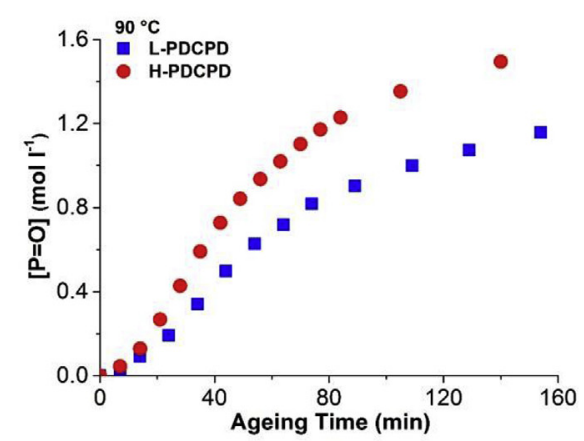

(d)

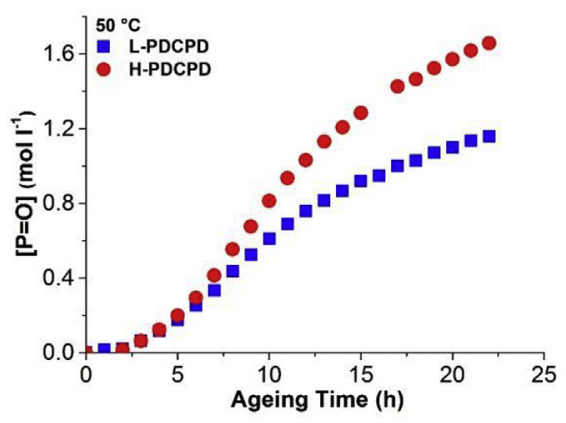

(f)

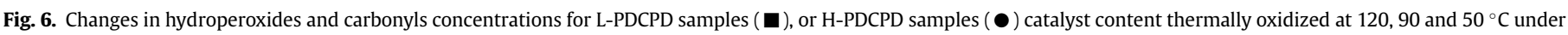
air.

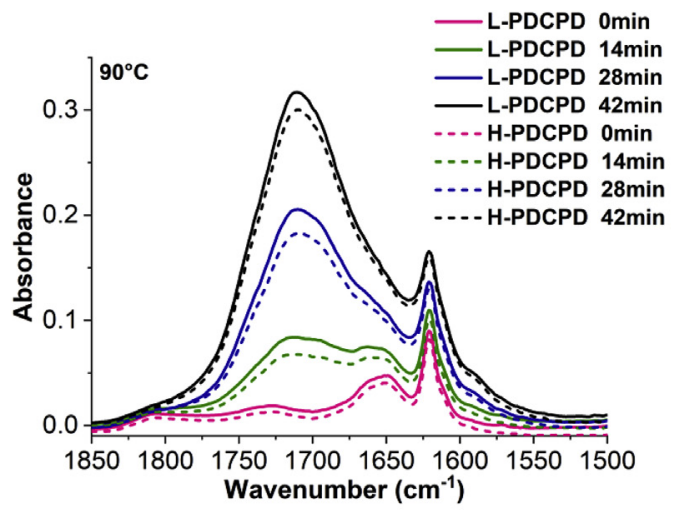

(a)

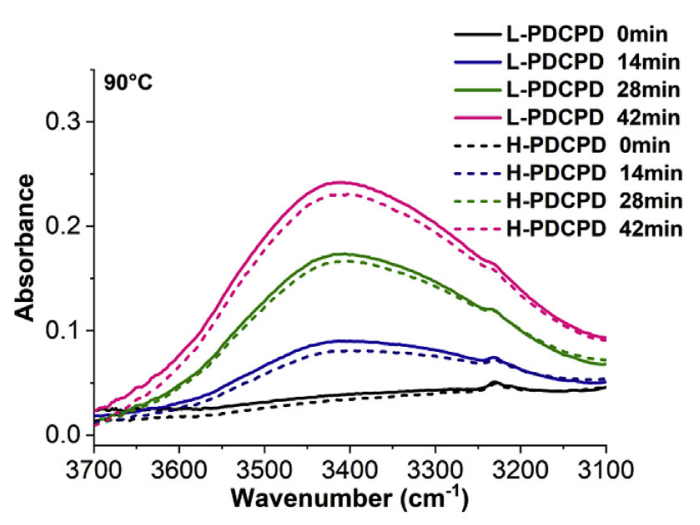

(b)

Fig. 7. FTIR spectra of L-PDCPD (full line, $13.3 \mu \mathrm{m}$ thickness) and H-PDCPD (dashed line, $12.8 \mu \mathrm{m}$ thickness) exposed at $90{ }^{\circ} \mathrm{C}$ under air. 


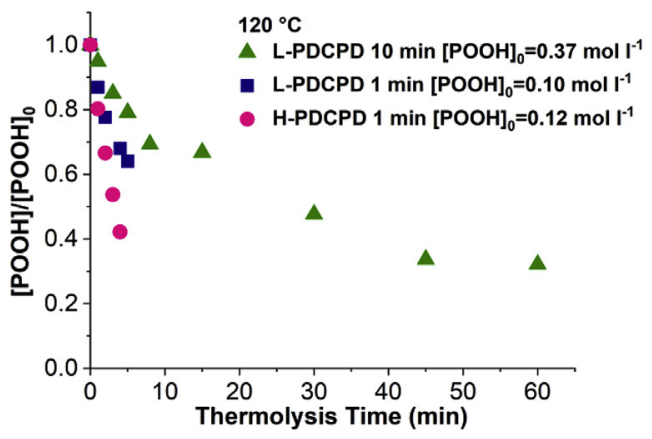

(a)

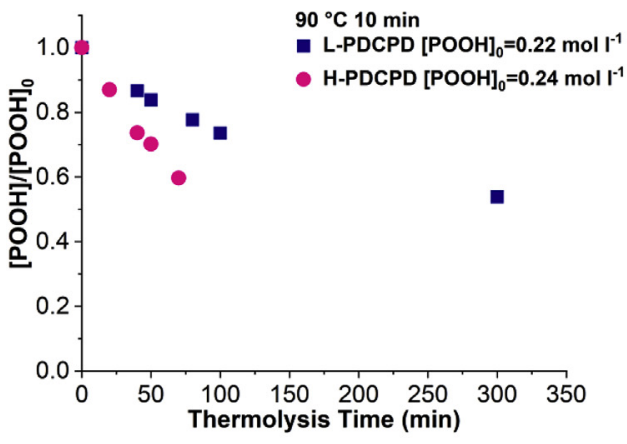

(b)

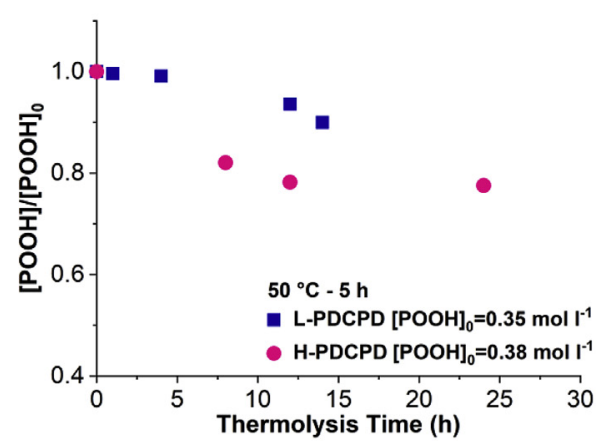

(c)

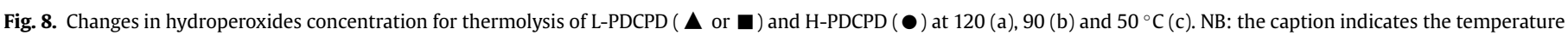
and time for ageing under air, and the corresponding $\mathrm{POOH}$ concentration after ageing and before thermolysis - see Fig. 6 .

Besides, an increase of carbonyl band centered at ca $1710 \mathrm{~cm}^{-1}$ is observed. Recalling the oxidation mechanisms of PDCPD explained in our last paper [2], the carbonyls mainly come from mechanisms detailed in Appendix 1.

1 the initiation step by unimolecular and bimolecular decomposition of hydroperoxides.

2 the bimolecular $\mathrm{POO}^{\circ}$ termination involving the disproportionation of two alkoxy radicals [18,19]:

$\mathrm{POO}^{\circ}+\mathrm{POO}^{\circ} \rightarrow \mathrm{P}=\mathrm{O}+\mathrm{POH}$

3 the decomposition of $\mathrm{POOP}^{\circ}$ (coming from the addition reaction of $\mathrm{POO}^{\circ}$ on double bonds), that rearrange into $\mathrm{PO}^{\circ}$.

Carbonyls formed from $\mathrm{POOH}$ decomposition are possibly aldehydes (and then carboxylic acids) whereas carbonyls formed from $\mathrm{POO}^{\circ}$ are possibly ketones [1]. As it will be seen later, only the unimolecular decomposition is influenced by catalyst residue. The fact that the carbonyl absorbance seems the same in L-PDCPD and H-PDCPD (Fig. 7a) seems to indicate that the contribution of

Unimolecular catalyzed: $\mathrm{POOH}+\mathrm{M}^{\mathrm{n}+} \rightarrow \mathrm{PO}^{\circ}+\mathrm{HO}^{-}+\mathrm{M}^{(\mathrm{n}+1)+}$ $\mathrm{POOH}+\mathrm{M}^{(\mathrm{n}+1)+} \rightarrow \mathrm{POO}^{\circ}+\mathrm{H}^{+}+\mathrm{M}^{\mathrm{n}+}$ unimolecular $\mathrm{POOH}$ decomposition is negligible in a first approach compared with the two other carbonyl sources.

Fig. 8 shows the thermolysis results of L-PDCPD and H-PDCPD.

\section{Discussion}

Our main aim is here to derive a set of rate constants for $\mathrm{POOH}$ decomposition from the thermolysis experiments reported in Fig. 4. Such rate constants can in principle be used in kinetic models for radical oxidation [1,2] wit the advantage of being independently and more precisely assessed than by the mere best curves fitting of overall oxidation kinetics.

\subsection{Theoretical investigation of the kinetics of $\mathrm{POOH}$ decomposition}

Firstly, let us recall that, in the frame of this work, it seems that there are three modes (from a kinetic point of view) for $\mathrm{POOH}$ decomposition $[20,21]$ :

Unimolecular uncatalyzed: $\mathrm{POOH} \rightarrow \mathrm{PO}^{\circ}+\mathrm{HO}^{\circ} \mathrm{k}_{10}$

Bimolecular uncatalyzed: $\mathrm{POOH}+\mathrm{POOH} \rightarrow \mathrm{POO}^{\circ}+\mathrm{PO}^{\circ}+\mathrm{H}_{2} \mathrm{O} \mathrm{k}_{1 \mathrm{~b}}$ 
The initiation step is composed of both uni- and bimolecular decomposition of $\mathrm{POOH}$. The specific identification of both uni- and bimolecular rate constants is thus intricate (apart maybe in the case of oxidation under oxygen excess where bimolecular initiation predominates, but the identification of $\mathrm{k}_{1 \mathrm{~b}}$ value remains somewhat dependent on the choice made for the other kinetic parameters in particular for propagation events).

It seems however that, depending on the level of hydroperoxide, reaction of radical creation from hydroperoxide decomposition are either predominantly uni- or bimolecular which makes it possible to selectively study each kind of initiation. Let us recall that:

$\mathrm{r}_{\text {uni }}=-\mathrm{d}[\mathrm{POOH}] / \mathrm{dt}=\mathrm{k}_{10}[\mathrm{POOH}]$

Eq. 3

$\mathrm{r}_{\text {uni catal }}=-\mathrm{k}_{1}\left[\mathrm{M}^{+}\right][\mathrm{POOH}]$

Eq. 4
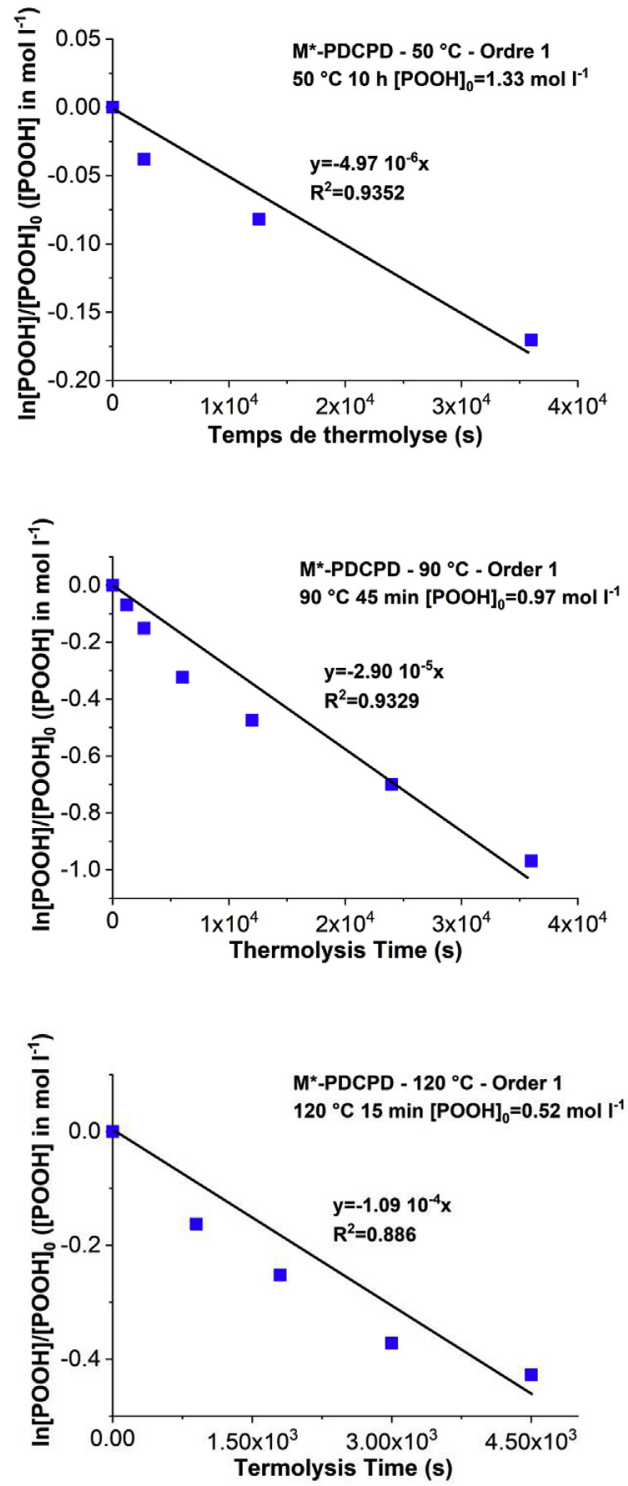

(a)

(b)

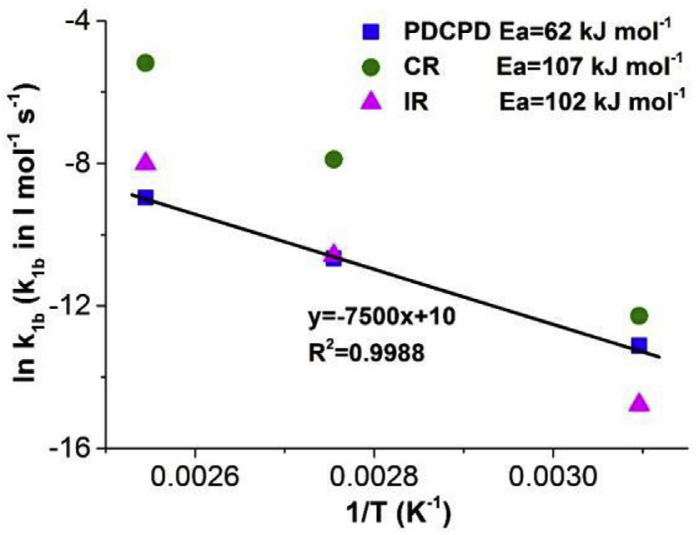

Fig. 10. Arrhenius plot of $\mathrm{k}_{1 \mathrm{~b}}$ values coming from thermolysis for PDCPD ( $\left.\mathbf{\square}\right), \mathrm{CR}(\bullet)$ [24], IR ( $\boldsymbol{\Delta}$ ) [17] from best fitting of oxidation curves.
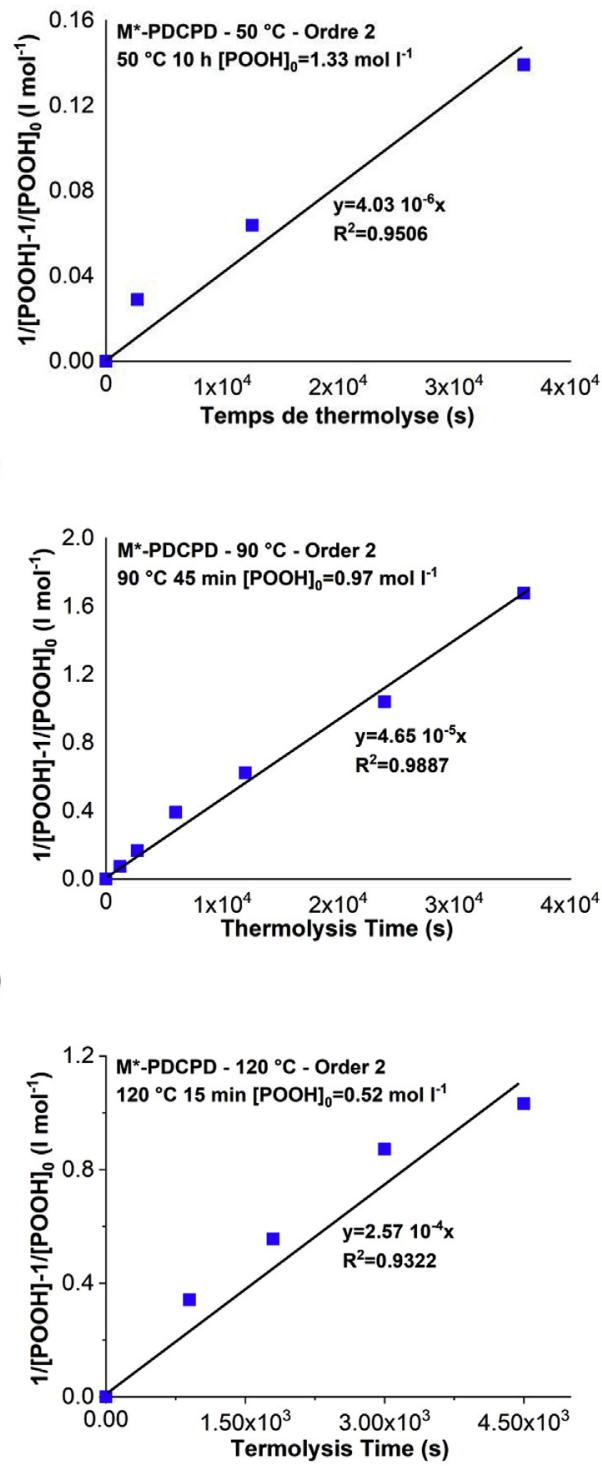

(c)

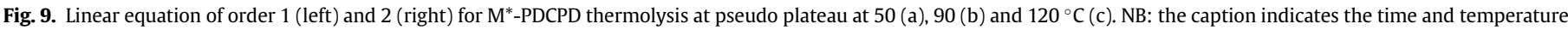
for ageing under air, and the corresponding $\mathrm{POOH}$ concentration after ageing and before thermolysis - see Fig. 2). 

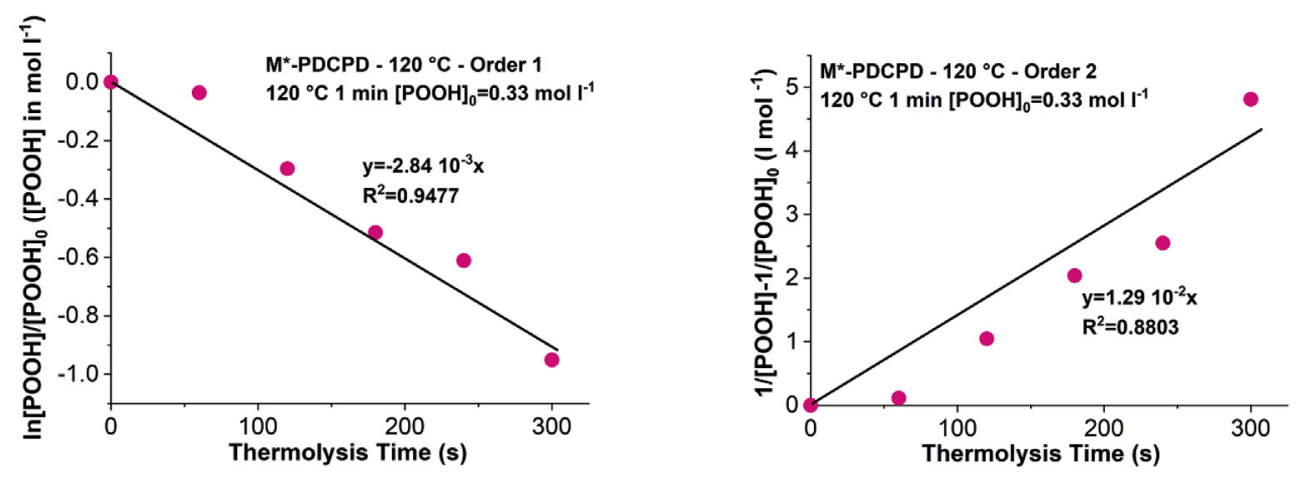

(a)
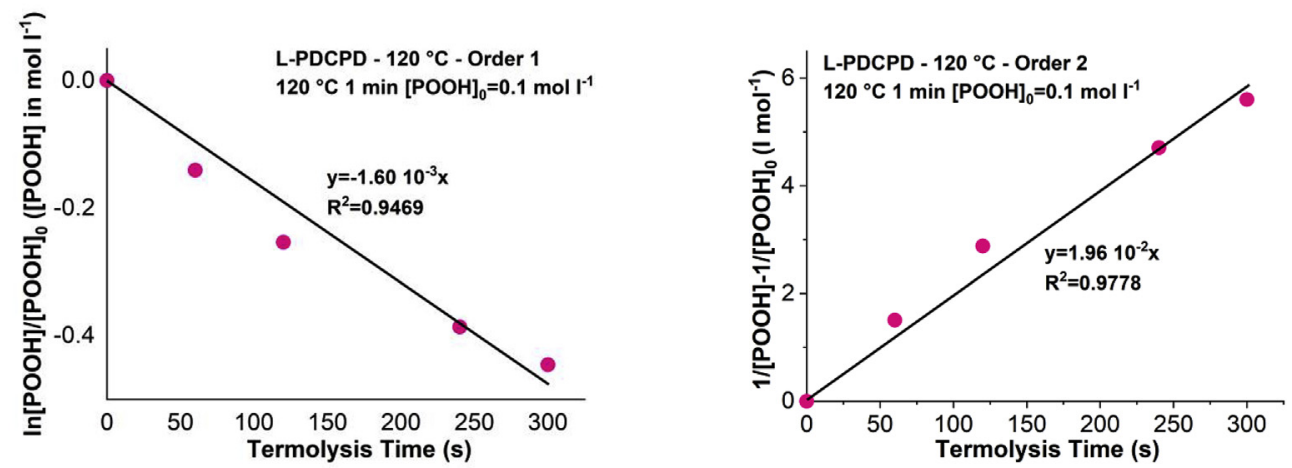

(b)
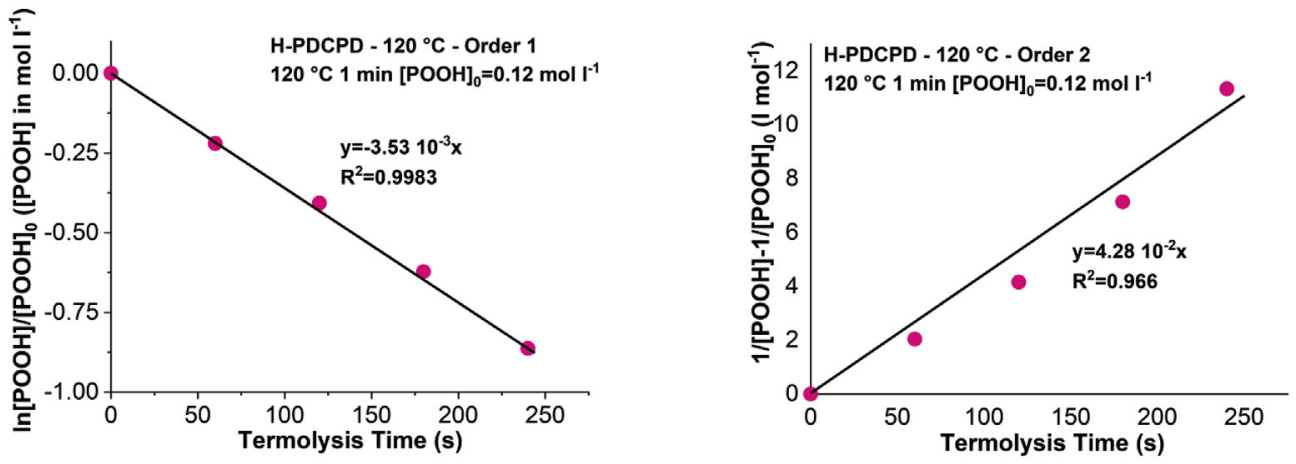

(c)

Fig. 11. Kinetic order 1 and 2 of thermolysis for $\mathrm{M}^{*}$-PDCPD samples aged $1 \mathrm{~min}$ at $120^{\circ} \mathrm{C}$ (a); for L-PDCPD samples aged 1 min at $120^{\circ} \mathrm{C}(\mathrm{b})$; for $\mathrm{H}$-PDCPD samples aged $1 \mathrm{~min}$ at $120^{\circ} \mathrm{C}(\mathrm{c})$. (NB: the caption indicates the ageing time and temperature under air, and the corresponding POOH concentration after ageing and before thermolysis - see Figs. 2 and 6).

( $\mathrm{k}_{1 \mathrm{c}}$ depending both on $\mathrm{k}_{\mathrm{c} 1}$ and $\mathrm{k}_{\mathrm{c} 2}$, and the concentration ruthenium catalysts in its several oxidations levels $\mathrm{Ru}^{2+}, \mathrm{Ru}^{3+}, \mathrm{Ru}^{4+} \ldots$ which is not developed here).

In other words, the unimolecular process is possibly described by an apparent rate constant [22]:

$\mathrm{k}_{1 \mathrm{u}}=\mathrm{k}_{10}+\mathrm{k}_{1 \mathrm{C}}\left[\mathrm{M}^{+}\right]$

Eq. 5

If $\mathrm{POOH}$ decompose in an unimolecular process, their concentration would change according to the well know equation:

$\ln [\mathrm{POOH}]=-\mathrm{k}_{1 \mathrm{u}} \mathrm{t}+\ln [\mathrm{POOH}]_{0}$

Eq. 6

according to which the half-life time for the decay of hydroperoxides ( $t_{1 / 2}$ uni $)$ is given by: $\mathrm{t}_{1 / 2}$ uni $=\ln 2 / \mathrm{k}_{1 \mathrm{u}}$

Eq. 7

If $\mathrm{POOH}$ decompose following a bimolecular process, the rate is given by:

$\mathrm{r}_{\mathrm{bi}}=-1 / 2 \mathrm{~d}(\mathrm{POOH}) / \mathrm{dt}=\mathrm{k}_{1 \mathrm{~b}}[\mathrm{POOH}]^{2}$

Eq. 8

$\frac{1}{[\mathrm{POOH}]}=2 k_{1 b} t+\frac{1}{[\mathrm{POOH}]_{0}}$

Eq. 9

And the half-life time for the decay of hydroperoxides $\left(t_{1 / 2} b i\right)$ is given here by:

$\mathrm{t}_{1 / 2 \mathrm{bi}}=1 /\left(2 \mathrm{k}_{1 \mathrm{~b}}[\mathrm{POOH}]_{0}\right)$

Eq. 10 

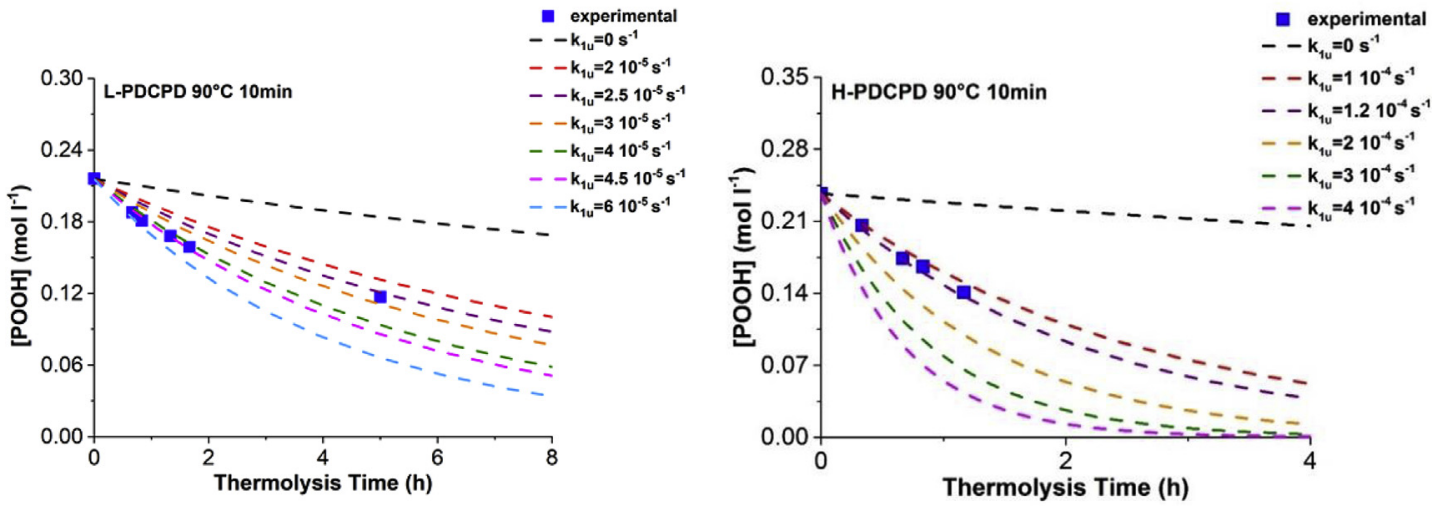

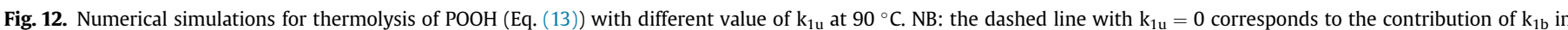
thermolysis at initially low $\mathrm{POOH}$ concentration.

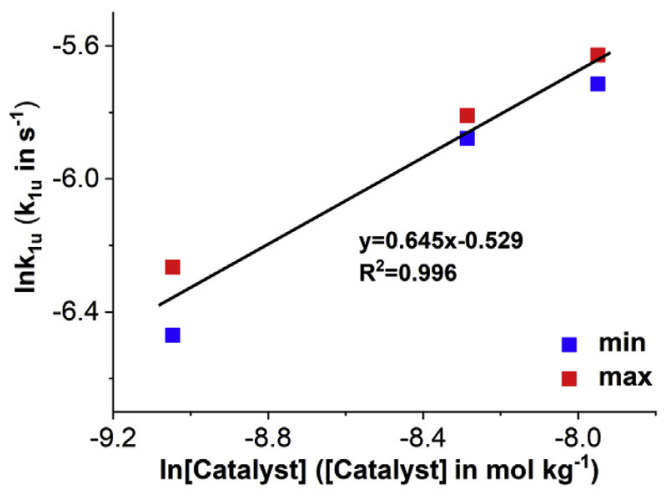

(a)

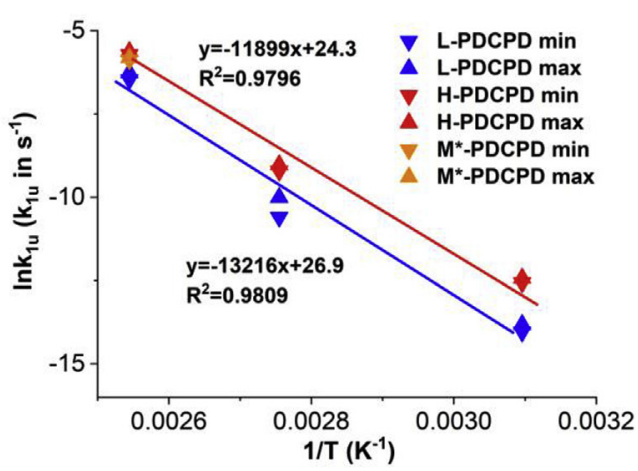

(b)

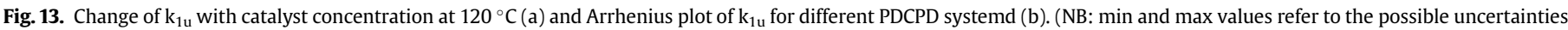
associated to the determination method of $\mathrm{k}_{1 \mathrm{u}}$ and are given in Table 2).

Let us note that in some cases, the situation is more complicated. For example, in PP, the decomposition takes place in two stages [23]. A fast decomposition is first observed, and is followed by a slow decomposition with a residual (persistent) concentration in $\mathrm{POOH}$ even at long thermolysis time. These two stages cannot be described by first- or second- order decay kinetics.

In our case, we considered separately thermolysis either at "plateau" (Fig. 4) or at early stage (Fig. 8). As results of experiments performed at $120^{\circ} \mathrm{C}$ show (Fig. 4c), the mechanism (uni- or bimolecular) is not the same since time to divide initial by 2 is not the same for samples in the plateau and in the low concentration domain. To better distinguish if kinetics obey order 1 or order 2 , residual hydroperoxide concentrations will be plotted in order 1 (ln $[\mathrm{POOH}] /[\mathrm{POOH}]_{0}$ vs time) or order $2\left(1 /[\mathrm{POOH}]-1 /[\mathrm{POOH}]_{0}\right.$ vs time) diagrams and we will use the value of the regression coefficient $\left(R^{2}\right)$ to decide which one of those two mechanisms was the most likely together with discussion of the physical validity of the proposed scenario.

\subsection{On the decomposition of $\mathrm{POOH}$ at high concentration (pseudo plateau)}

Despite some scatter, the regression correlation is higher for order 2 plots than order 1 (Fig. 9). It seems thus that $\mathrm{POOH}$ decomposition obeys a second order kinetics i.e. $\mathrm{POOH}$ decompose in a bimolecular way. This is well in line with the FTIR observations showing the maxima of hydroxyl absorbance at $3400 \mathrm{~cm}^{-1}$ (Fig. 7b).

A supplementary argument militating in favor of bimolecular process comes from the comparison of samples with various concentrations in catalysts residues. According to Fig. 6, there is no significant effect of catalyst on the oxidation kinetics in particular on the maximal $\mathrm{POOH}$ concentration. As justified in Appendix 2, this latter is expressed in steady state (under oxygen excess):

- in unimolecular mode:

$[\mathrm{POOH}]_{\max }=\frac{k_{3}^{2}[\mathrm{PH}]^{2}}{k_{1 u} k_{6}}$

- in bimolecular mode:

$[\mathrm{POOH}]_{\max }=\frac{k_{3}[\mathrm{PH}]}{2 \sqrt{k_{1 b} k_{6}}}$ 

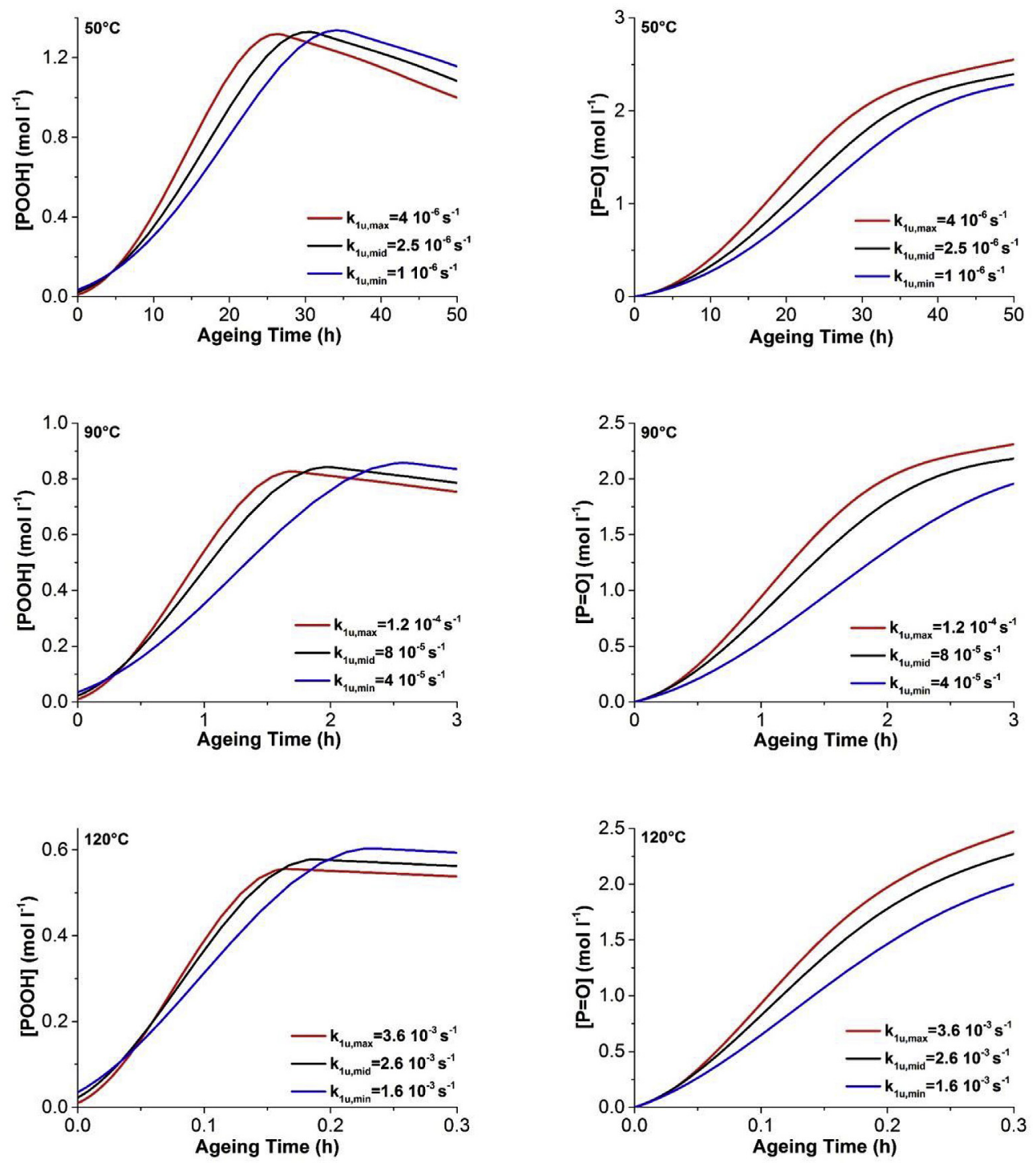

Fig. 14. Numerical simulations for thermolysis of $\mathrm{POOH}$ with different value of $\mathrm{k}_{1 \mathrm{u}}$ (and $[\mathrm{POOH}]_{\mathrm{t}=0}$ values from Table 1 ).

The maximal level of POOH for H-PDCPD and L-PDCPD catalyst concentration are the same so that:

- either $\mathrm{k}_{1 \mathrm{u} \text { high }}=\mathrm{k}_{1 \mathrm{u} \text { low }}$ which seems in contradiction with other results presented in the next paragraph (NB: the data at $50{ }^{\circ} \mathrm{C}$ would even suggest $[\mathrm{POOH}]_{\text {high }}>[\mathrm{POOH}]_{\text {low }}$ meaning $\mathrm{k}_{1 \mathrm{u}}$ high $<\mathrm{k}_{1 \mathrm{u}}$ low, which in contradiction with any physical meaning).

- or $\mathrm{k}_{1 \mathrm{~b} \text { high }}=\mathrm{k}_{1 \mathrm{~b}}$ low which seems more likely since bimolecular process can be considered as an auto-assisted decomposition process which is not influenced by metallic catalyst concentration.

Therefore $\mathrm{k}_{1 \mathrm{~b}}$ values were determined by the half of the slope of second order diagrams (Fig. 9). Interestingly, one sees that the observed values are well in line with $t_{1 / 2}$ values (Fig. 4) and Eq. (8): for example at $120{ }^{\circ} \mathrm{C}, \mathrm{t}_{1 / 2}$ is about $2 \mathrm{~h}$ which suggests $\mathrm{k}_{1 \mathrm{~b}}$ $\sim 1.3 \times 10^{-4} \mathrm{l} \mathrm{mol}^{-1} \mathrm{~s}^{-1}$ which is in good agreement with slope value (Fig. 9c). This validates for us the reasoning. Rate constants values were then plotted in an Arrhenius diagram (Fig. 10) together with other values from other substrates chosen because they contain $\mathrm{C}=\mathrm{C}$ double bonds. Even if values between all polymers have the same order of magnitude in the investigated temperature range between PDCPD, Isoprene Rubber (IR) and Chloroprene Rubber (CR), their activation energy values differ (62 $\mathrm{kJ} \mathrm{mol}^{-1}$ vs more than $100 \mathrm{~kJ} \mathrm{~mol}^{-1}$ for both elastomers). Values ranging from 70 to $120 \mathrm{~kJ} \mathrm{~mol}^{-1}$ are reported in the Denisov's monograph [20], with prefactor ranging from more than $10^{2}$ to less than $10^{13} \mathrm{lmol}^{-1} \mathrm{~s}^{-1}$ (vs about $2 \times 10^{4}$ here) and it remains to explain if the relatively low $E_{a}$ value for PDCPD comes from experimental uncertainty or a physical effect facilitating the bimolecular process. 


\subsection{On the low hydroperoxide concentration domain (in early period)}

The same theoretical treatment was applied for thermolysis experiments in the low concentration domain. Results are presented in Fig. 11. In the domain of "low" $\mathrm{POOH}$ concentration (i.e. below $0.3 \mathrm{~mol} \mathrm{l}^{-1}$ ), POOH kinetics are clearly faster than those observed for initial $\mathrm{POOH}$ concentration (before thermolysis) at the plateau which can receive two interpretations: either the $\mathrm{POOH}$ involved in reactions are not the same, or they display a different reactivity (in terms of uni- or bimolecular process). Both hypotheses will be discussed here below.

Gijsman and al [23] showed similar peroxides decomposition rates with an initially fast decomposition ascribed to peracids whereas the slow decomposing ones would be hydroperoxides. In fact, the species responsible of DSC exotherm seem to react with $\mathrm{SO}_{2}$ and DMS irrespectively of the thermal oxidation time. In other words, it was difficult for us to identify each of those species and which one predominates depending on the conversion degree.

It seems however clear that the hypothesis of second order decomposition for low concentration is hard to support. The time to destroy half of initially present hydroperoxides in the case of thermolysis in early period is actually faster than the one of thermolysis in pseudo plateau. For example, $t_{1 / 2}$ for $M^{*}$-PDCPD aged at $120{ }^{\circ} \mathrm{C}$ for $15 \mathrm{~min}$ is $2 \mathrm{~h}$ whereas $\mathrm{t}_{1 / 2}$ for $\mathrm{M}^{*}$-PDCPD aged at $120^{\circ} \mathrm{C}$ for $1 \mathrm{~min}$ is $4 \mathrm{~min}$. This agrees with the theoretical analysis $\left(\mathrm{t}_{1 / 2}\right.$ uni $=\ln 2 / \mathrm{k}_{1 \mathrm{u}}$ and $\mathrm{t}_{1 / 2}$ bi $\left.=1 / 2 \mathrm{k}_{1 \mathrm{~b}}[\mathrm{POOH}]_{0}\right)$. The "unimolecular" mechanism was thus envisaged but, apart in some cases (high temperature and high catalysis content), the first order adjustment was not perfect. We thus envisaged the following scenario: in the "low concentration domain" investigated here, both decomposition modes are concomitant, i.e.:

$\mathrm{d}[\mathrm{POOH}] / \mathrm{dt}=-\mathrm{k}_{1 \mathrm{u}}[\mathrm{POOH}]-2 \mathrm{k}_{1 \mathrm{~b}}[\mathrm{POOH}]^{2}$

with $\mathrm{k}_{1 \mathrm{~b}}$ determined from the decomposition in the high concentration region (see previous paragraph). The values of $\mathrm{k}_{1 \mathrm{u}}$ were thus determined from the procedure illustrated in Fig. 12, with a range of values [ $\mathrm{k}_{1 \mathrm{u} \text { min }}-\mathrm{k}_{1 \mathrm{u} \text { max }}$ ] aimed at taking into account the experimental uncertainties: for example at $90^{\circ} \mathrm{C}: \mathrm{k}_{1 \mathrm{u}}$ would fall between 2.5 and $4.510^{-5} \mathrm{~s}^{-1}$.

Then the $\mathrm{k}_{1 \mathrm{u}}$ values are plotted versus catalyst concentration and the ageing temperatures (Fig. 13). The (apparent) rate constants identified from this procedure display two interesting characteristics:

- they increase with the catalyst content. Such a feature is typical of an unimolecular process. According to Eq. (3), a value for uncatalyzed unimolecular process (denoted by $\mathrm{k}_{10}$ ) could be determined. The assumption of linear changes of $k_{1 u}$ with catalyst content is, however, for us an oversimplification since ruthenium can exist in several ionic forms $\left(\mathrm{Ru}^{2+}, \mathrm{Ru}^{3+}\right.$ and $\mathrm{Ru}^{4+}$ and Eq. (3) are a simplified description). The change of $k_{1 u}$ with the catalyst content could be described as $\ln \left[\mathrm{k}_{1 \mathrm{u}}\right]$ varies linearly with the $\ln$ [catalyst] (Fig. 13b). This characteristic leads to a new equation: $\mathrm{k}_{1 \mathrm{u}}=\mathrm{k}_{10}+\mathrm{k}_{1 \mathrm{C}}\left[\mathrm{M}^{+}\right]^{\mathrm{x}}$ with $\mathrm{x}=0.65$ consistently with previous papers [25].

- they obey Arrhenius law (Fig. 13b). If we consider separately data for L-PDCPD and H-PDCPD, prefactor (or frequency factor) range from $\mathrm{k}_{0}=4 \times 10^{10} \mathrm{~s}^{-1}$ (H-PDCPD) to $48 \times 10^{10} \mathrm{~s}^{-1}$ for LPDCPD with $E_{1 \mathrm{u}}=110 \mathrm{~kJ} \mathrm{~mol}^{-1}$ (for L-PDCPD) to $100 \mathrm{~kJ} \mathrm{~mol}^{-1}$ (H-PDCPD). The activation energies display the expected order of magnitude for first order rate constants for hydroperoxide decomposition $[15,20]$ (it seems possible however that catalyst presence induce a second order decrease). The prefactor values are lower than reported $[17,26]$ and surprisingly $\mathrm{k}_{1 \mathrm{u} 0}$ (LPDCPD) $>k_{1 u 0}$ (H-PDCPD), maybe due to the uncertainties of extrapolations in a Arrhenius diagram. It remains now to establish clear relationships between catalyst presence of prefactor and activation energies values.

$\mathrm{k}_{1 \mathrm{u}}$ and $\mathrm{k}_{1 \mathrm{~b}}$ rate constants can in principle be used in the previously established kinetic model [2] with the advantage of being independently estimated. An example is given in Appendix 2. To complete it to get closer of real cases, some side reactions might still be taken into account in the modeling. For example, it seems possible that the metallic impurities progressively deactivate in contact with oxygen, water or any oxidation byproduct, inducing the decrease of the apparent unimolecular constant $\mathrm{k}_{1 \mathrm{u}}$ towards the uncatalyzed rate constant $\mathrm{k}_{1 \mathrm{u} 0}$ (thus reducing even more the effect of catalyst on oxidation rate). Reversely, the possibility of $\mathrm{POOH}$ decomposition catalysis by oxidation products (alcohols, carboxylic acids) [27] occurring at high conversion degrees remains to be investigated. In any case, it seems that catalyst hardly influence the overall oxidation kinetics (Figs. 6 and 7) which is very well described by kinetics model (Fig. 14).

\section{Conclusions}

This paper present data related to the stability of hydroperoxides in PDCPD. Thermolysis experiments were performed to investigate the nature and kinetics aspects of the hydroperoxide decomposition reaction (uni- or bimolecular). Even if $\mathrm{POOH}$ seem to decompose mostly by bimolecular process, an unimolecular seems to be concomitant in the earlier exposure times, and would be favored by the use of high catalyst amount for the Ring Opening Metathesis Polymerization. The associated kinetics parameters were estimated and can be employed in a complete kinetic model for describing the whole oxidation process. The understanding of catalyst effect on thermal stability will be helpful to compound materials with the right tradeoff between fast polymerization and long term stability.

\section{Declaration of competing interest}

We hereby confirm that we have no conflict of interest with the submission of the paper « Thermal oxidation of poly(dicyclopentadiene) - Decomposition of hydroperoxides ».

\section{CRediT authorship contribution statement}

Jing Huang: Formal analysis, Investigation, Methodology, Writing - original draft. Wendy Minne: Investigation. Renata Drozdzak: Investigation, Project administration, Validation. Gilles Recher: Investigation, Project administration, Validation. Pierre Yves Le Gac: Formal analysis, Funding acquisition, Investigation, Methodology, Project administration, Writing - original draft. Emmanuel Richaud: Conceptualization, Formal analysis, Funding acquisition, Investigation, Methodology, Project administration, Supervision, Validation, Writing - original draft, Writing - review \& editing.

\section{Acknowledgements}

Agence Nationale de la Recherche is gratefully acknowledged for having funded this study (Project VRPOM - Vieillissement des Réseaux Polymérisés par Métathèse - 2016-2019). 


\section{Appendix 1}

The carbonyl functions can be produced from:

(1) the initiation step of thermal oxidation: hydroperoxide decomposition

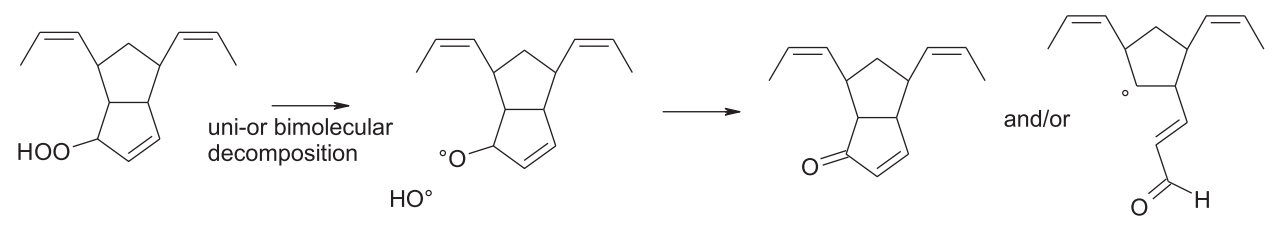

(2) the termination step involving several pathways [28]:

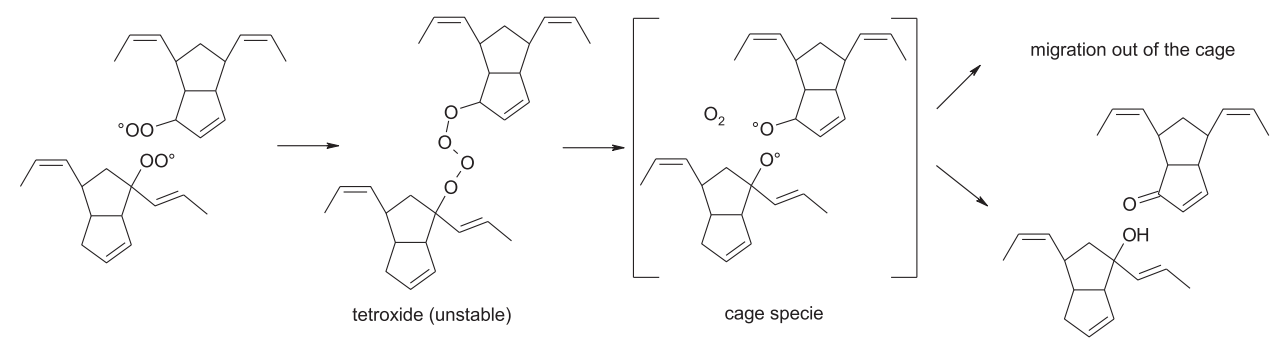

Alkoxy radicals migrating out of the cage can decompose later by $\beta$-scission to give an aldehyde:

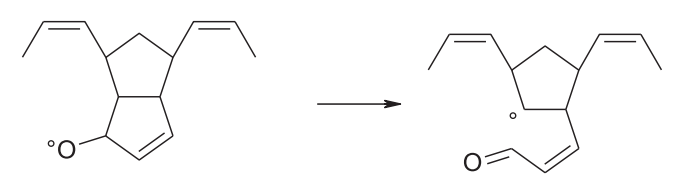

(3) the propagation step by addition reaction of $\mathrm{POO}^{\circ}$ to double bonds

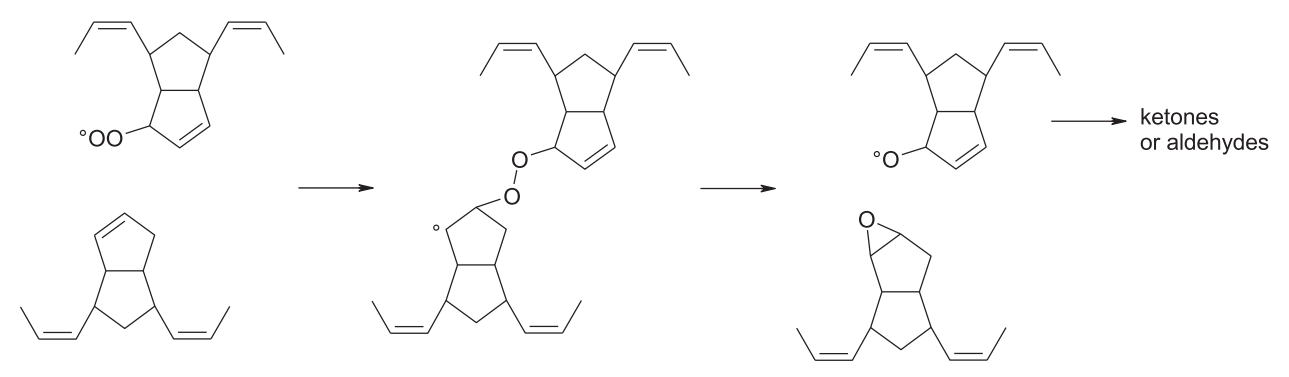




\section{Appendix 2}

For demonstrating Eqs. (11) and (12), let us consider the simplified scheme for uni- and bimolecular reactions [4]:

$\mathrm{POOH} \rightarrow 2 \mathrm{P}^{\circ} \mathrm{k}_{1 \mathrm{u}}$
$\mathrm{P}^{\circ}+\mathrm{O}_{2} \rightarrow \mathrm{POO}^{\circ} \mathrm{k}_{2}$
$\mathrm{POO}^{\circ}+\mathrm{PH} \rightarrow \mathrm{POOH}+\mathrm{P}^{\circ} \mathrm{k}_{3}$
$\mathrm{POO}^{\circ}+\mathrm{POO}^{\circ} \rightarrow$ inactive products $\mathrm{k}_{6}$

NB: $\mathrm{POOH}$ actually decomposes into $\mathrm{PO}^{\circ}$ and $\mathrm{HO}^{\circ}$ but both radicals transform into alkyl so that unimolecular equation is here given in a kinetically equivalent equation [4].

In steady state:

$$
\begin{aligned}
& \frac{d[\mathrm{POOH}]}{d t}=0 \Rightarrow \mathrm{k}_{1 \mathrm{u}}[\mathrm{POOH}]=\mathrm{k}_{3}\left[\mathrm{POO}^{\circ}\right][\mathrm{PH}] \\
& \frac{d\left(\left[\mathrm{P}^{\circ}\right]+\left[\mathrm{POO}^{\circ}\right]\right)}{d t}=0 \Rightarrow \mathrm{k}_{1 \mathrm{u}}[\mathrm{POOH}]=\mathrm{k}_{6}\left[\mathrm{POO}^{\circ}\right]^{2}
\end{aligned}
$$

Which gives Eq. (11).

In bimolecular case:

$$
\begin{aligned}
& \mathrm{POOH}+\mathrm{POOH} \rightarrow \mathrm{P}^{\circ}+\mathrm{POO}^{\circ} \mathrm{k}_{1 b} \\
& \mathrm{P}^{\circ}+\mathrm{O}_{2} \rightarrow \mathrm{POO}^{\circ} \mathrm{k}_{2} \\
& \mathrm{POO}^{\circ}+\mathrm{PH} \rightarrow \mathrm{POOH}+\mathrm{P}^{\circ} \mathrm{k}_{3} \\
& \mathrm{POO}^{\circ}+\mathrm{POO}^{\circ} \rightarrow \text { inactive products } \mathrm{k}_{6}
\end{aligned}
$$

In steady state:

$$
\begin{aligned}
& \frac{d[\mathrm{POOH}]}{d t}=0 \Rightarrow 2 \mathrm{k}_{1 \mathrm{~b}}[\mathrm{POOH}]^{2}=\mathrm{k}_{3}\left[\mathrm{POO}^{\circ}\right][\mathrm{PH}] \\
& \frac{d\left(\left[\mathrm{P}^{\circ}\right]+\left[\mathrm{POO}^{\circ}\right]\right)}{d t}=0 \Rightarrow \mathrm{k}_{1 \mathrm{~b}}[\mathrm{POOH}]^{2}=\mathrm{k}_{6}\left[\mathrm{POO}^{\circ}\right]^{2}
\end{aligned}
$$

Which gives Eq. (12).

\section{Appendix 3}

From these modeling results in Fig. 12, we got access to a range of $\mathrm{k}_{1 \mathrm{u}}$ values allowing the simulation of the thermal oxidation of LPDCPD and H-PDCPD (Fig. 14) and illustrating the model sensitivity to $\mathrm{k}_{1 \mathrm{u}}$. It also suggests that for the longer time, initiation is mainly bimolecular but with a small proportion of unimolecular branching.

\section{References}

[1] E. Richaud, P.Y. Le Gac, J. Verdu, Thermooxidative aging of polydicyclopentadiene in glassy state, Polym. Degrad. Stabil. 102 (2014) 95-104.

[2] J. Huang, A. David, P.-Y. Le Gac, C. Lorthioir, C. Coelho, E. Richaud, Thermal oxidation of Poly(dicyclopentadiene)- kinetic modeling of double bond consumption, Polym. Degrad. Stabil. 166 (2019) 258-271.

[3] V. Defauchy, P.-Y. Le Gac, A. Guinault, J. Verdu, G. Recher, R. Drozdzak, E. Richaud, Kinetic analysis of polydicyclopentadiene oxidation, Polym. Degrad. Stabil. 142 (2017) 169-177.

[4] L. Audouin, V. Gueguen, A. Tcharkhtchi, J. Verdu, "Close loop" mechanistic schemes for hydrocarbon polymer oxidation, J. Polym. Sci. Part A Polymer Chemistry 33 (1995) 921-927.

[5] E. Richaud, F. Farcas, P. Bartoloméo, B. Fayolle, L. Audouin, J. Verdu, Effect of oxygen pressure on the oxidation kinetics of unstabilised polypropylene, Polym. Degrad. Stabil. 91 (2006) 398-405.

[6] N.C. Billingham, M.N. Grigg, The kinetic order of decomposition of polymer hydroperoxides assessed by chemiluminescence, Polym. Degrad. Stabil. 83 (2004) 441-451.

[7] N.C. Billingham, E.T.H. Then, A. Kron, Chemiluminescence from peroxides in polypropylene: II. Luminescence and kinetics of peroxide decomposition, Polym. Degrad. Stabil. 55 (1997) 339-346.

[8] L. Zlatkevich, On the kinetic order of decomposition of polymeric hydroperoxides, Polym. Degrad. Stabil. 83 (2004) 369-371.

[9] G. Gutiérrez, F. Fayolle, G. Régnier, J. Medina, Thermal oxidation of claynanoreinforced polypropylene, Polym. Degrad. Stabil. 95 (2010) 1708-1715.

[10] E.M. Hoàng, N.S. Allen, C.M. Liauw, E. Fontán, P. Lafuente, The thermooxidative degradation of metallocene polyethylenes. Part 1: long-term thermal oxidation in the solid state, Polym. Degrad. Stabil. 91 (2006) 1356-1362.

[11] E.M. Hoàng, N.S. Allen, C.M. Liauw, E. Fontán, P. Lafuente, The thermooxidative degradation of metallocene polyethylenes: Part 2: thermal oxidation in the melt state, Polym. Degrad. Stabil. 91 (2006) 1363-1372.

12] Y. Ouldmetidji, L. Gonon, S. Commereuc, V. Verney, A differential scanning calorimetry method to study polymer photoperoxidation, Polym. Test. 20 (2001) 765-768.

[13] E. Richaud, F. Farcas, B. Fayolle, L. Audouin, J. Verdu, Hydroperoxide titration by DSC in thermally oxidized polypropylene, Polym. Test. 25 (2006) 829-838.

[14] D.J. Carlsson, R. Brousseau, D.M. Wiles, Reactions of sulfur dioxide with oxidized polyolefins, Polym. Degrad. Stabil. 15 (1986) 67-79.

[15] J.C.W. Chien, E.J. Vandenberg, H. Jabloner, Polymer reactions. III. Structure of polypropylene hydroperoxide, J. Polym. Sci. 1 Polym. Chem. 6 (1968) 381-392.

[16] J.C.W. Chien, H. Jabloner, Polymer reactions. IV. Thermal decomposition of polypropylene hydroperoxides, J. Polym. Sci. 1 Polym. Chem. 6 (1968) 393-402.

[17] X. Colin, L. Audouin, J. Verdu, Kinetic modelling of the thermal oxidation of polyisoprene elastomers. Part 1: unvulcanized unstabilized polyisoprene Polym. Degrad. Stabil. 92 (2007) 886-897.

[18] G.A. Russell, Deuterium-isotope effects in the autoxidation of aralkyl hydrocarbons. Mechanism of the interaction of peroxy radicals, J. Am. Chem. Soc. 79 (1957) 3871-3877.

[19] G.A. Russell, The rates of oxidation of aralkyl hydrocarbons. Polar effects in free radical reactions, J. Am. Chem. Soc. 78 (1956) 1047-1054.

[20] E. Denisov, I. Afanas'ev, Oxidation and Antioxidants in Organic Chemistry and Biology, CRC Press, 2005, p. 154. Chap. 4.

[21] F. Gugumus, Physico-chemical aspects of polyethylene processing in an open mixer6. Discussion of hydroperoxide formation and decomposition, Polym. Degrad. Stabil. 68 (2000) 337-352.

[22] E.A. Moelwyn-Hughes, The Kinetics of Reaction in Solutions, Oxford University Press, London, 1947, p. 297.

[23] P. Gijsman, J. Hennekens, J. Vincent, The mechanism of the low-temperature oxidation of polypropylene, Polym. Degrad. Stabil. 42 (1993) 95-105.

[24] P.Y. Le Gac, G. Roux, J. Verdu, P. Davies, B. Fayolle, Oxidation of unvulcanized unstabilized polychloroprene: a kinetic study, Polym. Degrad. Stabil. 109 (2014) 175-183.

[25] W.H. Richardson, Metal ion decomposition of hydroperoxides. IV. Kinetics and products of copper salt catalyzed decomposition of t-butyl hydroperoxide, J. Am. Chem. Soc. 88 (1966) 975-979.

[26] E. Denisov, I. Afanas'ev, Oxidation and Antioxidants in Organic Chemistry and Biology, CRC Press, 2005. Chap 4. Table 4.11.

[27] E. Denisov, I. Afanas'ev, Oxidation and Antioxidants in Organic Chemistry and Biology, CRC Press, 2005, p. 164. Chap. 4.

[28] R. Lee, G. Gryn'Ov, K.U. Ingold, M.L. Coote, Why are: Sec -alkylperoxyl bimolecular self-reactions orders of magnitude faster than the analogous reactions of tert -alkylperoxyls? the unanticipated role of $\mathrm{CH}$ hydrogen bond donation, Phys. Chem. Chem. Phys. 18 (2016) 23673-23679. 